\title{
ORGANIZAÇÃO POLÍTICA E CULTIVOS ILÍCITOS DE COCA NA BOLÍVIA \\ Uma abordagem etnográfica
}

\section{Rosinaldo Silva de Sousa}

Um fato que sempre causa forte impressão a qualquer um que tente compreender a história política boliviana é a instabilidade de seus governos. Alguns cientistas políticos bolivianos tentaram explicar a recorrência dos violentos dissensos na política institucional invocando uma incompatibilidade entre as normas consuetudinárias da maioria da população de origem indígena - o que chamarei aqui de cultura política - e os princípios filosóficos da ideologia democrática (Lazarte, 2002; Mansilla, 2003, 1993; Benavides, 2004; Ceres 1987, p. 100). Outros sugeriram que a sociedade boliviana seria incapaz de "produzir um sistema de organização política" adequado a conduzir sua "governabilidade" devido à incompatibilidade entre as expectativas de realização política da maioria de origem indígena e a orientação divergente do restante da população,

Artigo recebido em outubro/2009

Aprovado em abril/2010 mais ocidentalizada (Calderón e Santos, 1987, p. 109). Tais explicações são baseadas na evidente heterogeneidade cultural e na segmentação étnica do campo político no país.

Com o objetivo de contribuir para uma compreensão do cenário político contemporâneo na Bolívia, descreverei o funcionamento e a lógica de atuação do segmento que mais cresceu, nos últimos anos, em termos de representação política institucional: a maioria indígena-camponesa das etnias quéchua e aymara. A constatação da instabilidade política e da diversidade cultural desse país será apenas o ponto de partida da investigação. Minha estratégia de explicação das dificuldades de conciliação política no cenário boliviano percorrerá dois aspectos constituintes de sua cultura política: (1) a história de longa duração ${ }^{1}$ que justifica o uso da noção de "mundo andino" (Murra, 2002) como instrumento heurístico aplicado àquela realidade e (2) os acontecimentos relacionados com a intervenção 
estrangeira na "guerra contra as drogas". Quanto ao primeiro tópico, refiro-me a processos de longa duração que moldaram a mentalidade coletiva e sua cultura política: as formas pré-incaicas de administração da justiça, o papel proeminente do coletivo sobre o individual, as formas cooperativas de produção e a ideologia igualitária que ela implica. No segundo aspecto, o pano de fundo da etnografia será a questão da luta internacional antidroga, da qual a Bolívia tem sido um dos principais alvos.

Muitos especialistas em "mundo andino" já assinalaram a interdependência entre o passado e o presente na história das sociedades que o compõem, para citar alguns temas: na religião (Marzal, 1995; Van Den Berg e Schiffers, 1992) e na cosmologia (Zuidema, 1989; Duviols, 1973; Bouysse-Cassegne e Harris, 1987; Nash, 1979); nas relações de parentesco e economia (Mayer e Bolton, 1980; Ossio, 1992), na política (Flores Galindo, 1988; Platt, 1982; Orta, 2001; Choque e Mamani, 2001). A noção de "mundo andino", portanto, supõe a existência de formas estruturais de longa duração capazes de influenciar identidades coletivas e padrões de ações no presente. Neste artigo, apresentarei uma interpretação da cultura política boliviana atual ao descrever uma reunião em um "sindicato rural" da região do Chapare, a principal área de cultivo ilícito de folha de coca do país. "Sindicato rural" é o nome oficial dado às antigas comunidades rurais, após a Revolução de $1952 .{ }^{3}$ Essas comunidades rurais, presentes ao longo de toda região rural boliviana, são pensadas aqui como herdeiras diretas dos ayllus $^{4}$ e de suas formas de governar seus membros e território.

No entanto, o presente logicamente possui suas determinantes próprias na vida política boliviana. Neste caso, a perseguição internacional ao cultivo ilícito da folha de coca, associado às condiçôes econômicas deterioradas do campesinato boliviano geraram um cenário muito propício para o movimento social dos cocaleros bolivianos, a base do MAS (Movimiento al Socialismo) partido criado e chefiado pelo presidente Evo Morales. O local onde realizei meu trabalho de campo em julho de 2003, e durante o ano de 2004, é uma área relativamente recente de cultivo de coca na Bolívia. Conhecida internacionalmente como zona produtora de drogas, a regiāo do Chapare foi, nos últimos anos, a área de maior tensão social na Bolívia, devido às operações de erradicação dos cultivos de coca que opuseram os camponeses às forças policiais e exército. ${ }^{5}$ Esta zona de colonização desenvolveu-se graças ao cultivo de coca, destinado à produção ilícita de drogas, nas décadas de 1970 e 1980 . Devido ao surgimento de grande mercado consumidor ilícito, o Chapare tornou-se ponto de convergência de uma enorme massa camponesa sem-terra, ou proletários urbanos em processo de "recampesinização" (Arrieta Abdala, 1989). Ou seja, antes de migrarem, alguns dos novos cultivadores de coca já haviam sido inseridos em processos típicos da economia capitalista. Alguns deles, operários demitidos das minas, privatizadas ou falidas, eram representativos da então vanguarda esquerdista do país. ${ }^{6}$

\section{Uma reunião sindical: a base social da política indígena - cocalera}

Tratava-se apenas de uma reunião de rotina, como qualquer outra que ocorre mensalmente em todas as comunidades camponesas do Chapare. Entre os presentes, nove homens, onze mulheres e cinco crianças com idades entre seis meses e doze anos. O local era rústico, um barracão de cerca de trinta metros quadrados, coberto com telhas de barro. As paredes não vedavam totalmente o ambiente, assemelhavam-se mais a um muro baixo, pois deixavam uma abertura de cerca de um metro até o teto. Isso tornava o local bastante iluminado pelo sol da manhã, mas parcialmente desprotegido das folhas das árvores que eram levadas pelo vento para o piso de terra do prédio do sindicato de Bomborazama. Uma tábua toscamente aplainada sobre dois troncos estava recostada em uma das paredes e servia de assento para alguns; mulheres e crianças sentavamse ao chão; outros, apenas acocorados ou recostados nas paredes. No canto do salão, uma pequena mesa de madeira. Sobre ela, folhas de coca, alguns recortes de jornais, atas das reuniōes e, atrás da mesa, o dirigente sindical.

Ele não era um ancião da comunidade, ao contrário, era talvez o mais jovem dentre os presentes. Não mais que 30 anos. O cargo é rotativo e anual- 
mente a comunidade escolhe um de seus membros para ocupá-lo. Qualquer homem casado e possuidor de um terreno (chaco) é elegível. Todavia, não existe grande competição nem disputa para exercer a liderança neste nível da organização camponesa. Todos os homens terão a oportunidade de dedicar horas gratuitas de seu trabalho para servir à comunidade. $\mathrm{O}$ respeito que o dirigente sindical merece advém justamente de abdicar de uma parcela considerável de seu tempo, trabalho e recursos privados em prol da comunidade. O prestígio não é uma condição para desempenhar essa tarefa, é uma conseqüência dela.

O prédio do sindicato seria um lugar pouco intrigante não fosse por um pequeno cubículo em uma de suas extremidades. Formava um espaço de cerca de três metros de frente por um de fundo e era destinado à guarda provisória de alguma ferramenta ou material de trabalho, mas sua função principal era a reclusão de moradores da comunidade (comunarios), caso fosse necessário. Durante minha permanência em campo, a pena de reclusão não fora aplicada. Não obstante, a existência da cela atestava a autoridade comunitária na resolução autônoma de seus conflitos. Apesar de ser uma comunidade de menos de quarenta anos e muitos de seus habitantes terem nascido na própria zona subtropical, ainda é a cultura política dos habitantes das terras altas da Bolívia (altiplano), de onde emigraram os colonizadores do Chapare, que norteia grande parte da sua organização social. A resolução dos conflitos internos pela própria comunidade é uma tradição andina reconhecida pela Constitución Política del Estado (C. P. E.): "as autoridades naturais das comunidades indígenas e camponesas poderão exercer funções de administração e aplicação de normas próprias como solução alternativa de conflitos, em conformidade com seus costumes", mas ressalva que isso ocorrerá sempre que suas deliberações "não sejam contrárias a essa Constituição e às leis" (Constitución Política del Estado (C. P. E.), artigo 171, inciso III). Na prática, somente os casos em que uma das partes se dispõe a romper relaçóes com o restante do grupo, não se submetendo ao seu veredicto, são levados aos tribunais estatais.

A administração da justiça é uma característica das "comunidades corporadas" das terras altas da
América Latina (Wolf, 2003). Os ayllus do altiplano boliviano procuraram manter essa prerrogativa, a despeito da estratégica Reforma do virrey Francisco de Toledo (1569-1581), que dividiu os sistemas jurídicos na colônia entre "república de índios e de espanhóis". Isso resultou na predominância do sistema jurídico dos colonizadores sobre as leis andinas, tratadas apenas como "usos e costumes". Todavia, os interesses da metrópole em reduzir gastos administrativos propiciaram a preservação de alguma autonomia na administração da justiça nos assentamentos indígenas criados pelos colonizadores para fins de catequese, tributários e administrativos, as chamadas reducciones. Segundo a Reforma toledana, os ayllus pré-incaicos, subdivididos durante a colonização espanhola em conselhos administrativos conhecidos como cabildos indígenas, passaram a escolher seus governantes anualmente (Toledo, [1569] 1867, p. 157). Essa concessão da metrópole à autonomia administrativa dos ayllus acabou por criar respaldo documental, posteriormente usado por eles, para reivindicar território e autonomia jurídica durante a República (Rivera Cusicanqui, 1991; Platt, 1982).

Após a Revolução de 1952, as comunidades tradicionais sofreram nova modificação em sua terminologia administrativa e passaram a ser chamadas de "sindicatos rurais". A fim de dar execução a seu projeto de estender suas redes clientelistas ao campo, o "Estado de 52" duplicou a fonte de autoridade naquelas comunidades, sobrepondo, de maneira conflitante, o dirigente sindical, que deveria ser eleito anualmente, à autoridade tradicional dos jilaqatas, os chefes tradicionais dos ayllus.

Apesar da controvertida implantação dos sindicatos no altiplano, seu reconhecimento jurídico foi decisivo para a conformação do que reconhecemos hoje no Chapare como formas de administração herdadas dos ayllus, tal como resultaram de seu longo processo de transformação histórica. Depois da Revolução de 52, os sindicatos atuaram como meio de ingerência estatal nas comunidades indígenas das terras altas. Segundo Fernandez Osco (2000, p. 79), o sindicalismo projetou as leis bolivianas nessas comunidades como "um modelo de modernidade que o nacionalismo tentava levar às massas indígenas", relativamente isoladas. Em vez 
de recorrer exclusivamente à memória, a decisão jurídica de processos internos à comunidade passou a legitimar-se através das atas; ao mesmo tempo as multas econômicas substituíram parcialmente os açoites (chicotazos) e outras sanções físicas, como a mutilação. A pena capital foi combatida pelos representantes do Estado. Em muitas daquelas comunidades a forma dos sindicatos prevalece ainda hoje e pode ser largamente interpretada como inspirada na organização dos ayllus (Albó, 1972). No Chapare podemos constatar a adoção criativa dessa forma de organização política como um mecanismo adaptativo empregado pelos colonizadores em um meio natural e econômico desconhecido para eles, que acabavam de emigrar do planalto.

Tais indícios puderam ser notados em vários momentos daquela reunião em Bomborazama. $\mathrm{Na}$ quela manhã, a assembléia iniciou-se com a leitura da ata do mês anterior, feita por uma auxiliar do dirigente sindical. Foram pouco mais de trinta minutos sem interrupção, discorrendo sobre as resoluções adotadas na reunião anterior. Eram referentes a assuntos de interesse público sobre a gestão de recursos coletivos e decisões acerca de intrigas matrimoniais. Explicita-se neste último tópico a face tradicional da administração sindical que o Estado de 52 não conseguiu apagar do horizonte comunitário. Mais do que isso, a preocupação com a manutenção e a regulação dos matrimônios demonstra a interdependência entre as unidades domésticas no sistema produtivo comunitário. Pouquíssimas famílias cocaleras poderiam manter suas roças e padrão de subsistência isoladas das demais, devido às exigências da cooperação entre elas durante algumas etapas do ciclo agrícola. Recursos coletivos, como a força de trabalho de seus membros, tornam os temas de "foro íntimo" assuntos de interesse comum. A pauta da reunião corrente já estava pronta e seus itens foram abordados ao final da leitura da ata.

Uma das decisões tomadas na reunião anterior tratava da convocação do antigo ocupante de um terreno abandonado na comunidade. A posse e ocupação de terrenos (chacos) é uma das causas mais freqüentes de conflitos em toda a região do Chapare, assim como em outras zonas rurais da Bolívia. Para a família camponesa, a terra é o principal meio de produção e a base de qualquer economia de subsistência. Logo, a sobrevivência da comunidade depende do bom aproveitamento desse recurso. $\mathrm{O}$ primeiro caso tratado na reunião foi concernente ao chaco deixado ocioso, por mais de oito anos, pela família que residia nele. $\mathrm{O}$ sindicato pretendia declarar o terreno "caduco", o que significaria a subseqüente transmissão dos direitos sobre aquele terreno para alguém disposto a habitar e assumir obrigações naquela comunidade. A antiga moradora estava presente especialmente para tentar assegurar sua posse. Ela agora vivia em Cochabamba, ${ }^{7}$ onde explorava um pequeno comércio de bebidas alcoólicas. Antes mesmo do início da reunião, ela já havia declarado que não pretendia voltar a viver naquela terra, dadas as atuais circunstâncias de restrições ao cultivo de coca: "naquela terra não dá frutas e coca não se pode mais plantar!", argumentava ela. Não seria fácil convencer aos demais sobre a manutenção do terreno improdutivo. Afinal, passavam por dificuldades semelhantes, mas persistiam na empresa colonizadora. A vontade de permanecer em suas terras explica a dedicação dos cocaleros à causa da descriminalização dos cultivos de coca. A grande demanda por folha de coca foi a principal razão de ser da colonização; por este motivo seu livre cultivo é visto pelos migrantes como a salvação de seu empreendimento nos trópicos.

A forma de integração dos cocaleros chapareños ao mercado inclui alternativas de ganhos econômicos provenientes de outras funções temporárias, desde que não implique déficit para as atividades sociais e políticas devidas à comunidade. $\mathrm{O}$ afastamento de uma unidade produtiva do convívio comunitário, por um tempo julgado excessivamente longo, é prejudicial ao equilíbrio da divisão do trabalho coletivo. Deixar de participar ativamente na vida comunitária configura abandono do terreno e conseqüente abdicação dos direitos sobre ele. Por essa razão, a argumentação da comerciante não sensibilizava os cocaleros, eles não a viam mais como parte da comunidade e não estavam dispostos a assumir qualquer prejuízo decorrente daquela situação. Como camponeses, eles não são simpáticos a que seus vizinhos adotem estilos de vida destoantes ao que a comunidade espera de seus membros. Não se trata apenas do clássico "conservadorismo camponês", mas de assegurar que a participação de to- 
dos na vida coletiva possibilite a divisão eqüitativa das tarefas cotidianas. A ideologia igualitária não se sustentaria na vida prática se as necessidades básicas não encontrassem satisfação nos limites da economia camponesa.

$\mathrm{O}$ dirigente não precisou apresentar o caso aos demais, pois já o conheciam e haviam deliberado sobre ele na reunião anterior, assim como em conversas informais durante seus afazeres cotidianos. Limitou-se a comunicar a requisição da posse do terreno e estipulou um valor a ser pago pelas benfeitorias que restavam nele. As terras do trópico foram concedidas às famílias pelo Estado por intermédio do sindicato, o qual se reservava o direito de tomá-las de volta em casos como aquele. $\mathrm{O}$ sindicato camponês possui personalidade jurídica (C. P. E., Artigo 171, inciso II). Quando disputas jurídicas são levadas ao tribunal do Estado, o sindicato é quem sofre ou move o processo judicial, o que faz do requerente ou réu um opositor da comunidade. $\mathrm{O}$ argumento recorrente dos sindicatos, quando se tratam de disputas sobre terras, é o mesmo proclamado desde a Ley de Reforma Agrária de 1953: "a terra é de quem a trabalha".

Após a Reforma Agrária que se seguiu à Revolução de 1952, muitos latifúndios foram desapropriados por um critério que figura na atual Constituição boliviana: "o trabalho é a fonte fundamental para a aquisição e a conservação da propriedade agrária" (C.P.E., artigo 166). Os colonizadores do Chapare receberam suas terras porque havia uma intenção estatal de povoar regiōes tidas como "vazias", mas supostamente aptas à agricultura e/ou à pecuária. De acordo com a expectativa governamental, a colonização de regiôes subtropicais permitiria amenizar a pressão sobre a terra no altiplano. Agora que o produto agrícola que possibilitou a colonização de amplas porçôes da selva boliviana está sob restrição internacional, surgiram novos desafios para aqueles que pretendem permanecer fiéis ao projeto de vida nos trópicos.

Era esse projeto que estavam tentando manter os cocaleros, quando exigiam a desocupação do chaco improdutivo em sua comunidade. Após apresentação da proposta do sindicato, a ex-camponesa foi a primeira a falar: "Rogo a vocês que me perdoem a demora em vir aqui, já faz muito tempo que não tenho paz na minha vida, Deus sabe". Ela fez uma longa explanação contando as desventuras de sua vida, desde quando partira de Bomborazama. "Meu marido não serve para nada, apenas sabe embriagar-se o dia todo, e eu com um filho doente quase já não consigo trabalhar. Não tenho quem me ajude e o dinheiro que ganho mal dá para as despesas que são tantas, vocês sabem". Seguiu contando sobre um acidente que sofrera e que a deixou sem poder locomover-se por semanas, fez questão de mostrar a cicatriz em sua perna esquerda. Passaram-se quase trinta minutos e ela apenas limitavase a dizer, quanto ao motivo de sua presença ali: "não posso perder esse terreno, que custou tanto esforço para conseguir". Por fim, começou a chorar enquanto prosseguia reclamando sobre sua suposta condição financeira miserável. Os presentes não demonstraram nenhuma comoçãa. Ao que tudo indica, aquele era o comportamento esperado, e a ela foi dada a oportunidade de desenvolver o drama, sem nenhuma interrupção, até quando julgasse que tudo havia sido dito.

Ela não questionou as regras da comunidade nem tentou invalidar o pleito. Sua estratégia foi a de se mostrar de acordo com a petição e apelar para a sensibilização dos presentes. Concordava que seu problema devia ser resolvido exclusivamente através do sindicato e não contestou sua legitimidade. Pediu um prazo de um ano, até que seu filho mais velho pudesse residir no chaco, e garantiu que estava disposta a pagar as contribuiçóes devidas imediatamente.

Muitos dos camponeses acreditam que o tempo de fartura dos cultivos de coca voltará um dia. Essa é uma das razôes da persistência em continuar trabalhando em seus terrenos, ainda que eles apresentem atualmente baixo rendimento para outros cultivos. Mesmo aqueles que abandonaram seus chacos, para dedicar-se a outras atividades longe dos trópicos, mostram-se esperançosos quanto ao retorno dos tempos em que se poderá novamente cultivar a extensão de coca que sua força de trabalho permitir. Talvez por isso não fosse uma solução para a requerente romper com a comunidade e tentar assegurar a posse da terra nos tribunais. Isso inviabilizaria um possível retorno para cultivar coca "quando a situação mudar". 
Os comunarios já haviam decidido quem poderia vir a ocupar aquele terreno, caso sua atual possuidora não encontrasse uma solução satisfatória para o problema. A falta de força de trabalho para cumprir as tarefas produtivas e demais trabalhos públicos gera preocupação entre os cocaleros do Chapare, pelo menos desde que se intensificou a repressão policial sobre os cultivos de coca, no final da década de 1980. Entretanto, a carência de força de trabalho na comunidade não inibiu os critérios de recrutamento de novos moradores, baseados em uma comunhão de valores culturais capazes de assegurar o consenso sobre a obediência às normas comuns estabelecidas.

Apesar de a condição camponesa poder ser definida analiticamente a partir de "uma relação estrutural, não [a partir de] um determinado conteúdo de cultura" (Wolf, 2003, p. 121), a escolha de quem poderá residir na comunidade não está baseada exclusivamente na posição social do pretendente, mas também em aspectos diacríticos característicos do jogo de inclusão/exclusão, típicos dos processos étnico-culturais (Barth, 1997). As decisões individuais dos colonizadores tropicais são amplamente orientadas pela comunidade, tal como nas "comunidades corporadas"; mas, diferentemente delas, é permitido e aprovado o ingresso de novos membros em virtude da carência de força de trabalho. A receptividade, não obstante, limita-se a membros de origem indígena, tornando fundamental o fator étnico-cultural, o qual foi deixado de lado na caracterização "estrutural" (Wolf, 2003, p. 123) dos tipos de campesinato latino americano. O "Estado de 1952" transformou as "comunidades indígenas" em "camponesas", segundo o argumento de que o termo "índio" tinha ecoado durante anos de opressão pré-revolucionária, tornando-se uma palavra carregada de significados negativos. A equivalência dos termos "indígena" e "camponês", presente na legislação e no senso comum dos citadinos bolivianos, faz parte da história política da nação. Contudo, ela não deve levar-nos a subestimar os critérios de inclusão/exclusão baseados na etnicidade - eles constituem o fundamento da apropriação comunal da terra.

A importância da diferença cultural foi recentemente admitida pelo Estado boliviano. Em uma emenda à Constituição, em 1994, a Bolívia declarou-se multiétnica e pluricultural. A sua população quéchua e aymara designam-se ora como indígenas, ora como camponeses, dependendo de qual aspecto queiram ressaltar. As crianças que brincam nas praças dos povoados chapareños chamam-se jocosamente uma a outra de "indígena!", para declarar algum tipo de incapacidade do companheiro. Portanto, o termo é ambíguo, mas o avanço político desse segmento tem tornado a condição indígena uma estratégia para a coesão política, transformando novamente sua significação. ${ }^{8}$

A substituição oficial do apelativo étnico por um termo que descreve a condição socioeconômica foi parte da política do Estado boliviano, desde a fundação da República (1825). No entanto, a recusa em reconhecer juridicamente o índio, nas sucessivas Constituições bolivianas até a Revolução de 52, nunca havia significado sua incorporação igualitária como cidadão nacional. Esse status lhe foi bloqueado por meio do estabelecimento de prerrequisitos socioeconômicos (possuir alta quantia em dinheiro, emprego ou ser proprietário de algum imóvel, ser alfabetizado) que lhe impediam a plena participação na vida política. Somente a partir de 1961 a cidadania política passou a exigir apenas inscrição no "Registro Cívico", tornando os descendentes dos povos originários habilitados para exercerem prerrogativas da cidadania boliviana.

Nas comunidades do Chapare, os sindicatos se auto-intitulam organizações camponesas, não obstante, como mencionei, as regras de aceitação de novos membros obedecerem mais a critérios diacríticos de ordem étnica. Todavia, o simples pertencimento étnico não é suficiente para manter-se membro de uma comunidade camponesa, como a comerciante quéchua de Cochabamba estava comprovando. Quando ela terminou sua defesa naquela manhã, uma camponesa que estava amamentando tomou a palavra e sugeriu a ela que aceitasse a compensação oferecida pela comunidade e deixasse aquela terra para alguém disposto a trabalhá-la. A desvantagem nessa opção era que a multa acumulada por conta da sua prolongada ausência às reuniões e outras obrigaçôes comunitárias provavelmente ultrapassariam o montante que ela teria a receber da comunidade. Fez-se um cálculo de suas dívidas 
desde o ano de 1998, pois as atas dos anos anteriores não estavam disponíveis no momento. Além dos dias que faltara, somaram-se também reuniōes extras, ampliados ${ }^{9}$ e as despesas do sindicato com o envio de seus membros às mobilizações e seminários de capacitação. Cada modalidade possuía um valor. $\mathrm{O}$ valor da dívida foi convertido imediatamente pela devedora para o dólar ao câmbio do dia, 150 dólares. Ela resolveu saldar ali mesmo metade de sua dívida com o sindicato, evidenciando que sua condição financeira não era tão precária. Os presentes não pareciam surpresos com isso, todos sabiam que demonstrar carência e humildade faz parte do comportamento público valorizado, mesmo quando se trata dos mais prósperos camponeses ou comerciantes. A ostentação de riqueza cria um diferencial indesejável entre pessoas que precisam ser iguais para trocar força de trabalho entre si.

"Isso não resolve nosso problema" disse o mais velho dos presentes (ex-líder sindical, 61 anos): "Precisamos de alguém que nos ajude com todo o trabalho que temos aqui; não é suficiente pagar as contribuições, quando precisamos de gente para abrir novos caminhos e efetuar reparos nos que já existem". Nesse momento veio à tona certo ressentimento de algumas das mulheres. Uma delas (uma jovem mãe de três filhos, residente há dois anos na comunidade) resmungou amargamente que não adiantava deixar um chaco sem quem o cuide, pois há famílias necessitando da terra e dispostos a ajudar nos afazeres coletivos. Diante disso, a excamponesa não teve outra saída a não ser prometer ocupar novamente o terreno enviando seu irmão, o qual ficaria disponível para tomar parte na vida comunitária a partir do próximo mês. Com essa promessa, e o pagamento da primeira parte da dívida com o sindicato, o problema foi temporariamente encerrado e o acordo foi assinado em "ata de compromisso".

O pacto precisa ser consensual; se não houver acordo, novas discussões terão lugar até que ele seja obtido. O tempo não limita os argumentos relevantes e a ideologia igualitária reinante nessas assembléias autoriza a qualquer um dos membros a tomar a palavra. Não é incomum que uma polêmica atravesse o dia e se prorrogue por outro. Se o dissenso for sobre questôes de terra, a ausência de um entendimento razoável para uma das partes levaria o caso ao Juzgado de Villa Tunari, ${ }^{10}$ um tribunal especializado em questões fundiárias. Tive oportunidade de acompanhar uma disputa semelhante naquele Juzgado. No dia do julgamento, pelo menos trinta camponeses da comunidade requerente aglomeravam-se em frente ao prédio do tribunal. $\mathrm{O}$ indivíduo que desejava manter a posse de seu terreno ocioso foi aconselhado pelo juiz a aceitar uma pequena indenização e encerrar o litígio. Ele concordou. Findo o caso, um dos advogados disse-me que aquela era a solução menos desvantajosa para o requerente. Sua situação poderia tornar-se mais crítica, caso o tribunal o apoiasse contra o grupo, pois a indisposição geral manifesta contra ele inviabilizaria qualquer empreendimento futuro naquela comunidade, seja dele, seja de alguém ligado a ele.

A propriedade coletiva do território sempre foi a principal fonte da autoridade tradicional nas comunidades andinas. De forma semelhante, também nas zonas de colonização, o controle e a distribuição dos lotes foram deixados a cargo dos sindicatos rurais. Um território próprio é requisito indispensável para que se exerça a autoridade delegada a cada sindicato. Por essa razão, a delimitação de suas fronteiras é questão freqüentemente tratada nas reuniōes. Esse foi o tema seguinte na reunião que estou narrando. $\mathrm{O}$ sindicato vizinho estava requerendo terras que os comunarios de Bomborazama alegavam pertencer a seu sindicato. Nenhuma decisão foi tomada a respeito, apenas concluiu-se que o mais sensato seria levar o problema à Central de Eterazama, órgão camponês que congrega todos os sindicatos de área a que pertencia o sindicado de Bomborazama. O número de sindicatos afiliados a uma Central varia, na região do Chapare, entre 15 a 65, de acordo com a densidade populacional de cada zona. O dirigente sindical informou-me depois que os desacordos sobre limites territoriais poderiam ser encaminhados ao Juzgado de Villa Tunari, caso não se chegasse a um consenso na própria Central.

A terra só se tornou um recurso escasso no Chapare após o auge da produção de coca destinada à indústria ilícita de cocaína, na década de 1980 . Antes, bastava a filiação a um sindicato para obter lotes de cerca de dez hectares por família. Feito isso, 
adquiria-se automaticamente a responsabilidade de tomar parte nas atividades comunitárias: assumir cargos sindicais, trabalhos públicos, participação em bloqueios de estradas, manifestações, freqüência às reunióes e pagamento de taxas de manutenção do sindicato. Quando a demanda por folha de coca para a fabricação de cocaína cresceu, os agricultores adotaram um sistema de trabalho de partidários, que cultivavam uma parcela da terra que a unidade doméstica original não conseguia trabalhar. O produto era dividido entre o proprietário e seu partidário na proporção de cinqüenta por cento. Nas décadas posteriores, quando o programa de erradicação e a interdição policial fizeram baixar o preço da coca, muitos bens de consumo voltaram a assumir seu preço de mercado, inclusive a terra. Em 1996, entrou em vigor uma nova lei de terras, a Ley Inra, por meio dela alguns trabalhadores rurais obtiveram titulação de terras. O Instituto Nacional de la Reforma Agraria (Inra) tem distribuído, nos últimos anos, títulos de propriedade para os moradores do Chapare, mas os sindicatos cocaleros são contrários a essa política. Afirmam que é um tipo de intromissão do Estado nos assuntos internos das comunidades. A posse privada da terra enfraqueceria o poder dos sindicatos rurais, isto é, a capacidade coletiva de decisão sobre o uso da terra dentro dos limites do sindicato.

Esse tipo de rejeição da regulação do Estado é característico das pretensões de autonomia reclamada pelas comunidades rurais na Bolívia. A lógica do individualismo sob a qual se baseiam as intervenções do Estado (Dumont, 1993) é conflitante em vários aspectos com os princípios coletivistas reinantes no mundo rural andino. Segundo alguns camponeses, a difusão da propriedade individual da terra abriria caminho para sua transformação em mercadoria, o que poderia levar à perda de controle comunal sobre os possíveis compradores da terra. Sem controle sobre seus membros, a manutenção da autoridade tradicional ficaria inviabilizada, assim como a reprodução social das unidades domésticas. A política e a economia não são dissociáveis na vida camponesa boliviana. Por isso, a reunião sindical é o local onde se decide o que fazer dos terrenos vacantes: o direito liberal e a economia de mercado não atuam como os principais parâmetros das de- cisões sindicais sobre seu território. A necessidade de simetria entre unidades produtivas e o gerenciamento coletivo do território ajudam a compreender também a incompatibilidade entre a lógica produtiva coletivista tradicional e a lógica de acumulação privada comum à atividade ilícita de produção de drogas. Tal incompatibilidade fornece uma pista para entendermos o apelo limitado que o engajamento direto na produção de pasta-base exerce sobre o produtor de coca, desde que inserido em uma comunidade e com acesso a terra e ao mercado. Conforme já mostrou Izquierdo (2001) em seu estudo em comunidade colombiana assediada por narcotraficantes, a lógica tradicional e a luta pela manutenção de um modo de vida camponês podem constituir obstáculo considerável à penetração, nessas comunidades, de padrôes de consumo e de acumulação típicos do narcotráfico. ${ }^{11}$

O prosseguimento da reunião em Bomborazama foi interrompido pela chegada de dois jovens vestidos com batas brancas, que cumprimentaram os camponeses em quéchua. As mulheres ficaram um pouco inquietas com o que eles diziam. Logo compreendi que eram agentes de saúde vacinando contra a febre amarela. $\mathrm{O}$ dirigente autorizou a vacinação, que iniciou por ele próprio.

Após a partida dos agentes de saúde, todos começaram a pagar sua contribuição mensal, cobrada por unidade doméstica. A quantia devida mensalmente seria o suficiente para comprar quatro refeições nos restaurantes populares de Villa Tunari. $\mathrm{O}$ valor da multa por cada falta à reunião também corresponde à mesma quantia; seu pagamento, entretanto, não desobriga o ausente da contribuição mensal, criteriosamente anotada no livro de contas do sindicato. Todos tinham acesso a ele, sendo possível saber o valor do débito dos ausentes, assim como orgulhar-se por estar "em dia".

Estando os presentes quites com o sindicato, a reunião prosseguiu com um informe cultural. $\mathrm{O}$ padre de Villa Tunari abriria uma pequena biblioteca em Eterazama; os livros poderiam ser emprestados ao custo de 2,00 bolivianos por exemplar. Já que o tema era a igreja, o dirigente enveredou por assuntos religiosos, uma de suas predileções em conversas pessoais. Ele transmitiu um recado do padre sobre a freqüência às missas e discorreu sobre 
o concubinato. Esse dado não era sem relevância naquele momento, pois semanas atrás fora o motivo de uma reunião extraordinária em Chipiriri, um povoado próximo. Naquela ocasião, os comunarios decidiram arbitrar um caso de possível adultério de uma mulher cujo marido se encontrava ausente por vários meses, por razão de trabalho. $\mathrm{O}$ problema envolvia também um funcionário da escola local, recém-chegado. Decidiu-se que a moradora deveria seguir uma vida de esposa virtuosa ou deixar a comunidade. Tanto ela como o funcionário em questão foram convocados e estavam presentes na reunião em Chipiriri. Vê-se que a vida privada está subsumida à coletiva nas comunidades indígenas. Considera-se que situações como essas podem interferir negativamente nas relaçôes produtivas.

Outro tópico da pauta fora iniciado. Retomava uma discussão da reunião anterior. Tratava-se de um processo que tramitava na justiça, contra alguns dirigentes sindicais do Chapare. Ele não entrou em detalhes, e nunca insisti por informações sobre o assunto. Uma das providências que a Federação do Trópico de Cochabamba tomou quanto à questão em juízo foi organizar um "seminário de capacitação jurídica", a fim de evitar futuros processos contra os dirigentes cocaleros. Enquanto discorria sobre o tema, acrescentou que as prisões desses sindicalistas eram ilegais e que o Estado desrespeitava sua própria Constituição Política. $\mathrm{O}$ assunto suscitou, visivelmente, a indignação dos camponeses, o que indica que a estrutura sindical do Chapare é muito mais que uma forma de gerenciar assuntos paroquiais. É uma rede de relações políticas, divididas em células relativamente autônomas para resolver algumas questóes, mas interdependente no que tange a questôes de interesse geral para os cocaleros. Quanto à organização do sindicato como estrutura política representativa dos interesses dos cocaleros, cada um funciona como difusor de informações a seus membros. Essa cadeia de transmissão é responsável pela rápida mobilização coletiva. Ela também conecta a comunidade com o mundo exterior. A indignação dos membros do sindicato ensejou temas correlatos. Entre eles, o das torturas executadas pelo "exército boliviano, comandado pelos gringos”. Houve comparação dessa situação com a da impunidade dos senhores espanhóis, durante o período colonial.
Ainda sobre seminários, conclamou-se a mais uma arrecadação de fundos para enviar uma representante do sindicato a uma oficina de capacitação de lideranças femininas, em Cochabamba. Conforme determinação do partido dos cocaleros (MAS Movimiento Al Socialismo), todo sindicato devia enviar sua representante à oficina. A multa estipulada por maioria no ampliado dos dirigentes das centrais foi de 50 bolivianos a serem pagos pelo sindicato absenteísta. Esse valor seria suficiente para custear uma estada de dois dias em Cochabamba, desde que a alimentação e a hospedagem estivessem a cargo da Federação, o que ocorreria no caso daquela oficina de capacitação. Depois de dois meses decorridos, a camponesa selecionada entregaria ao sindicato alguns documentos aprovados pela Federação e, em cerca de quarenta minutos, leria anotações sobre os seminários a que assistira. Apesar de sua apresentação ter sido improvisada e pouco esclarecedora, todos dedicaram atenção a ela. As resoluçôes adotadas nesse seminário incluíam: "defender a cultura e idioma originários"; "lutar contra a injustiça social, contra os partidos políticos neoliberais e a favor da verdadeira democracia”.

A reunião em Bomborazama avançava e já passava do meio dia. A folha de coca estava sendo consumida desde o início da reunião. Uma mulher espargiu alguns punhados de folhas sobre a mesa do líder sindical, na qual restavam apenas os talos centrais das folhas já consumidas, que eram retirados cuidadosamente antes de inseridas na boca. Havia também recortes de jornais que no momento apropriado seriam trazidos para o pequeno público. $\mathrm{O}$ dirigente podia tratar de assuntos que considerava auxiliares na formação da "consciência política” da comunidade. Dessa maneira, ele iniciou uma discussão sobre a Alca (Associação de Livre Comércio para as Américas). Explicou as tentativas norte-americanas para ampliar sua influência comercial e qualificou como negativo o impacto de novas tecnologias de produção de alimentos: "os Estados Unidos estão enfermos, pois não consomem alimentos naturais como os bolivianos". Alimentos transgênicos foram duramente criticados. Em seguida, o dirigente anunciou o assunto mais esperado em todas as reuniōes dos camponeses chapareños: "o tema coca". 
O primeiro comunicado foi o fato, sabido informalmente por todos, de que "os mercados [de coca das cidades] de Eterazama e Sacaba continuam funcionando (com autorização governamental), mas segue-se a erradicação". Esse paradoxo fora explorado semanas antes, na reunião da Alcaldia (prefeitura) de Villa Tunari, por Evo Morales. A erradicação forçosa dos arbustos de coca é o motor da indignação cocalera, por isso provoca a exacerbação dos sentimentos. Nos discursos do líder máximo dos cocaleros, durante aquele período, havia a tentativa de relacionar a erradicação de coca aos outros "temas estruturais" do país, principalmente a exportação de hidrocarbonetos. As mensagens de Evo Morales durante as reuniões das lideranças do partido são transmitidas pelos dirigentes sindicais às bases, em suas reuniōes ordinárias, como aquela de Bomborazama.

Talvez devido à minha presença, a discussão tenha mudado para as tradições ancestrais relacionadas com o hábito do acullico. ${ }^{12}$ Esse é um discurso que qualquer cocalero maneja com destreza. Passaram cerca de 45 minutos discutindo a utilidade da folha de coca e suas propriedades benéficas: auxilia a concentração durante tarefas diárias, afasta a sonolência, a fome e o cansaço; ajuda a manter os dentes limpos e saudáveis; é fonte de cálcio e proteínas. Por fim, falaram da clássica distinção entre coca e cocaína, eximindo os bolivianos da culpa pelo "vício dos gringos". Segundo as intervenções acaloradas dos presentes, a droga na Bolívia poderia ser comparada aos inexistentes armamentos químicos do Iraque. "Não passa de uma desculpa dos ianques para se apossarem dos recursos naturais da Bolívia”. "É só uma justificativa para interferir nos assuntos internos do país". Não negaram, todavia, a existência de fabricação de cocaína no país, mas enfatizaram que a organização sindical não apóia camponeses envolvidos diretamente em negócios ilegais. Sobre isso, afirmaram que "a cocaína não faz parte da nossa cultura ancestral”. ${ }^{13}$

Após vários membros expressarem suas opiniōes, o dirigente recorreu a uma matéria de jornal onde se lia que, conforme decisão do Congresso Nacional boliviano, as violações dos direitos humanos, cometidas pelas forças norte-americanos na Bolívia, não poderiam ser julgadas no país. "Isso significa que os gringos massacram nosso povo e ficam impunes!", indignou-se uma mulher. Todos então concordaram que deveriam acionar imediatamente os camponeses do país para uma manifestação contra essa disposição legal. "Todos devemos unir-nos para protestar contra essa decisão do governo".

No entanto, os protestos contra o governo, nesse período, estavam sendo contidos pela cúpula do partido cocalero. Havia uma trégua estratégica para preservar a tranqüilidade no cenário político, às vésperas da realização de um plebiscito para decidir sobre os termos da exportação do gás natural. Durante o ano de 2004, pude presenciar a impaciência dos cocaleros para retomar os bloqueios de estradas no Chapare, enquanto o líder, Evo Morales, procurava persuadi-los da inocuidade desse protesto. Ele argumentava que uma das pontes dessa estrada havia cedido em razão das fortes chuvas: "a estrada já estava bloqueada naturalmente". Tais fatos demonstram como, em razão dos acordos políticos, a liderança do partido precisa conter e canalizar os sentimentos coletivos para alcançar objetivos que não estão ligados diretamente à sua subsistência cotidiana. Para as bases, o tema da coca tem proeminência sobre qualquer outro, pois das decisões a esse respeito depende a reprodução das unidades domésticas. Como notou Wolf (1984, p. 12), em seu estudo a respeito das rebeliôes camponesas, a mobilização da sua "vanguarda" depende mais de fatores específicos da vida local do que de grandes questôes nacionais. Entretanto, os presentes na reunião em Bomborazama constataram que, para solucionar suas questôes locais mais urgentes, teriam de se envolver com problemas que transcendem os limites de sua aldeia: "devemos tomar o governo do país". Isso conduziu ao tema das eleições presidenciais. Naquele momento, foi solicitada ajuda financeira para a campanha presidencial "do nosso companheiro Evo". Estimou-se que, se cada camponês doasse 1,00 boliviano, seriam arrecadados o equivalente a 18 mil dólares. A proposta foi prontamente acolhida com esperança e otimismo. Tanto as bases como a liderança do Movimiento al Socialismo orgulham-se da sua auto-suficiência econômica. Talvez por essa razão as inúmeras contribuições exigidas não sejam vistas como um 
ônus que subtrai os parcos recursos econômicos da unidade doméstica, mas como investimento no "nosso instrumento político".

Quando o debate sobre o "tema coca" dava sinais de esgotar-se, o relógio marcava três da tarde. Nenhuma refeição fora servida, a não ser para os lactentes. Para as crianças de mais idade, ofereceram pães. Várias bolsas de coca, com cerca de 15 gramas cada, haviam sido consumidas. A tese de que a coca ameniza a fome foi constatada mais uma vez, pelo menos teoricamente para mim. Para terminar, o dirigente lembrou que já havia adquirido a torneira a ser instalada, na mesma tarde, em um ponto próximo ao campo de futebol da comunidade. Ele a retirou de sua mochila e a exibiu; três dos presentes acertaram os detalhes do encontro para executar a tarefa, após o almoço. Por fim, perguntou se ainda havia mais algum assunto a ser tratado. Um dos participantes, percebendo que a reunião chegara ao final, acrescentou encorajando aos demais: "hay que seguir plantando coca!". Todos concordaram, despediram-se e seguiram para seus chacos.

\section{Considerações finais}

A organização sindical, calcada nos ayllus, reflete a forte influência de valores tradicionais andinos na organização política dos cocaleros. A ideologia igualitária (simetria) e a predominância da coletividade sobre indivíduo são elementos importantes para compreendermos os princípios da cooperação política dos cocaleros.

A entrada na vida política institucional, com a criação do partido MAS, tornou o entrelaçamento entre política e organização social cocalera mais evidente. A interdependência entre as unidades domésticas, baseadas na ajuda mútua durante as atividades de trabalho (ayni) e nos mutirōes (mink'a), assim com a estrutura sindical, foram eficazes para organizar a colonização do trópico chapareño. $\mathrm{O}$ partido político também se valeu da preexistente estrutura sociopolítica, moldando-se a ela.

A descrição etnográfica de uma reunião sindical aqui empreendida exemplificou essa conjunção de fatores, o que também pode ser plenamente observável nas reuniōes mensais da Federação dos
Colonizadores do Chapare Tropical, da Federação dos Colonizadores do Chimoré, ou de qualquer outra Federação ou Alcaldia (prefeitura) que esteja sob controle dos cocaleros. ${ }^{14}$ Em Villa Tunari, por exemplo, até mesmo a sede do sindicato está em desuso; as reuniōes foram transferidas para o salão principal do prédio da Alcaldia, desde então administrada pelo partido cocalero.

O substrato cultural favorável a uma noção particular de atuação política talvez seja a chave para compreender a prática de chamada "democracia direta" (Mayorga, 2003; Gutiérrez et al., 2002; Ramírez, 2004; Escobar, 1987; Lazarte, 1987), a qual supóe uma participação ativa e constante da população nas decisōes políticas mais importantes. A necessidade do consenso que orienta a prática política nas reuniôes sindicais restringe o espaço para a manipulação das bases sindicais por parte de segmentos partidários mais voltados para questôes nacionais. O crescimento do partido no cenário nacional é o reflexo da capacidade de mobilização das bases e de seu auto-entendimento enquanto sujeitos políticos centrais no país. Quando desenhei para um cocalero, em forma piramidal, a hierarquia entre as várias instâncias de sua organização sindical-partidária, ele só concordou com a representação gráfica depois de tê-la virado de ponta-cabeça: o topo, segundo ele, representava os sindicatos rurais; os líderes do partido estariam na parte inferior. Embora não devamos tomar essa indicação como um dado objetivo, não podemos ignorar a ideologia igualitária como um valor presente na auto-representação dos cocaleros como atores políticos.

A divisão entre os segmentos do partido voltados para a nação e aqueles voltados para os interesses comunitários promete ser uma das causas mais freqüentes de tensões no partido. O fato de o partido cocalero ter chegado ao governo do país, amplificou essa contradiçãa. Os interesses dos sindicatos de base exigem decisōes altamente complexas sobre o livre comércio e produção da folha de coca, por exemplo. O governo vê-se forçado a radicalizar suas posiçôes perante a representação diplomática estadunidense em La Paz. A superação ou não dessa tensão depende, principalmente, de como o governo de Evo Morales lidará com sua principal bandeira de luta, pela qual se tornou conhecido e repre- 
sentativo de amplos setores da população indígena rural e urbana. Os desdobramentos das políticas relacionadas com a folha de coca e seus efeitos na relação bilateral com os Estados Unidos, e multilateral, são capítulos da história boliviana que ainda estão sendo escritos.

Um quadro elucidativo sobre a vida política boliviana atual deve levar em consideração tanto a história profunda daquela região andina, como a história recente, incluindo o drama gerado pelas políticas internacionais antidrogas. Nesta etnografia, levei em consideração esses dois fatores apenas na medida em que foram úteis para elucidar os anseios e a forma de expressão política da base camponesaindígena, a principal responsável pelas mobilizações populares características da Bolívia.

\section{Notas}

1 Utilizo a noção de longa duração, oriunda da Escola dos Annales, para enfatizar as estruturas profundas cuja lógica pode conflitar com lógicas econômicas e políticas modernas. Um exemplo do impacto de formas pré-modernas de ação política conformando noções peculiares de democracia pode ser encontrado no estudo de Putnam, Leonardi e Nanetti (1993) sobre a democracia na Itália.

2 A "ley 1.008", que regula o cultivo de coca na Bolívia, dividiu as áreas de cultivo como de cultivo legal, excedente e ilícito. A região em que realizei essa pesquisa, Chapare, enquadrada como área de cultivo excedente, foi o principal alvo da política de erradicação de cultivo de coca nas últimas duas décadas.

3 A Revolução de 1952 é considerada um fato da maior importância na história política boliviana no século XX. Ela marca o fim do monopólio de poder da oligarquia mineira e latifundiária e a ampliação de direitos políticos a uma grande parcela indígena até então marginalizada.

4 Ayllus são grupos de parentela extensa e configuram comunidades corporadas.

5 Situada na parte norte-central da Bolívia, o Chapare possui bosques subtropicais entre os departamentos (estados) de Santa Cruz e Cochabamba, totalizando sua extensão em 24.500 quilômetros quadrados. Para a região do Chapare estima-se uma população de 327.616 habitantes (INE apud Lessmann, 2003).
6 O desmantelamento das empresas de mineração estatais deveu-se principalmente às reformas estruturais de Paz Estenssoro, em meados da década de 1980. A queda do preço do estanho no mercado internacional, seguida da demissão de milhares de operários das minas, enfraqueceu a maior força organizada da sociedade civil até então: a Central Obrera Boliviana (COB), cujo protagonismo foi assumido atualmente pelos cocaleros.

7 Cidade distante cerca de nove horas de ônibus desde o povoado de Eterazama, nas proximidades da comunidade em questão.

8 Sobre a utilização da cultura nos movimentos políticos na América Latina, ver Alvarez, Dagnino e Escobar (2000).

9 Assembléias que congregam vários sindicatos rurais.

10 Povoado sede da administração municipal e que concentra os serviços do Estado disponível para os comunarios de Bomborazama.

11 Em artigos sobre a penetração do crime organizado nas favelas do Rio de Janeiro (Sousa, 2004; 2006a) também assinalei que as estruturas de poder preexistentes são importantes para a compreensão da forma que o narcotráfico assume em cada contexto particular. As relaçôes sociais e políticas podem ser contrárias ao estabelecimento das estruturas de poder necessárias ao funcionamento do comércio ilícito, ou favorecê-las.

12 Nome dado ao consumo tradicional de coca.

13 Para mais detalhes sobre as relações entre produção de coca e a fabricação de pasta-base, ver Sousa (2006).

14 As prefeituras do Chapare são dirigidas pelos próprios cocaleros desde meados da década de 1990, quando concorreram pela primeira vez aos postos.

\section{BIBLIOGRAFIA}

ALBÓ, Xavier. (1972), "Dinámica en la estrutura intecomunitaria de Jesús de Machaca". América Indigena, 32, México.

ALVAREZ, Sonia; DAGNINO, Evelina \& ESCOBAR, Arturo (orgs.). (2000), Cultura e politica nos movimentos sociais latino-americanos. Belo Horizonte, Editora da UFMG.

ARRIETA ABDALA, Mario. (1989), "Utopía andina, desproletarización y recampesinización", in Mario Arrieta Abdala e Carlos F. Toranzo 
Roca (orgs.), Nueva derecha y desproletarización en Bolivia, La Paz, Unitas/Ildis.

BARTH, Fredrik. (1997), "Grupos étnicos e suas fronteiras: a organização social da diferença cultural", in Philippe Poutignat e Jocelyne Streiff-Fenart (eds.), Teorias da etnicidade, São Paulo, Editora da Unesp.

BENAVIDES, Jimena Costa. (2004), "La 'Guerra del Gas': representaciones sobre neoliberalismo y defensa de los recursos naturales em la crisis política de octubre de 2003". Coleción Monografias, Centro de Investigaciónes Postdoctorales Facultad de Ciencias Económicas y Sociales, Universidad Central de Venezuela. Caracas.

BLANES, Jose. (1983), De Los Valles al Chapare: estratégias familiares en un contexto de cambios. Cochabamba, Ceres.

BLANES, J. \& Flores, Gonzalo. (1982), Campesino, migrante y 'colonizador': reproducción de la economía familiar en el Chapare tropical. La Paz, Ceres.

BOUYSSE-CASSEGNE, T. \& Harris, Olivia. (1987), "Pacha: en torno al pensamiento aymara", in Bouysse-Cassegne et al. (orgs.), Trés reflexiones sobre el pensamiento andino, La Paz, Hisbol.

CALDERÓN, Fernando \& Santos, Mario dos. (1987), "Entre el pacto progresivo y el ordem impuesto", in René A. Mayorga, Democracia a la Deriva, La Paz, Ceres/Clacso.

CERES. (1987), "Las ciencias sociales y la problemática de la democracia", in René A. Mayorga, Democracia a la Deriva, La Paz, Ceres/Clacso.

CHOQUE, Maria Eugenia \& MAMANI, Carlos. (2001), "Reconstitución del ayllu y derechos de los pueblos indígenas: el movimiento indio en los Andes de Bolivia". The Journal of Latin American Anthropology, 6 (1).

DUMONT, Louis. (1993), o individualismo:uma perspectiva antropológica da ideologia moderna. rio de Janeiro, rocco.

DUVIOLS, Pierre. (1973), "Huari y Llacuaz: agricultores y pastores: un dualismo prehispánico de oposición y complementariedad". Revista del Museo Nacional, 39, Lima.

ESCOBAR, Filemón. (1987), "La experiencia histórica de la participación obrera a partir de la revolución de 1952", in René A. Mayorga, Democracia a la Deriva, La Paz, Ceres/Clacso.

FERNÁNDEZ OZCO, Marcelo. (2000), La Ley del Ayllu: práctica de jach'a justicia y jisk'a justicia (Justicia Mayor y Justicia Menor) en comunidades aymaras. La Paz, Fundación Pieb.

FLORES GALINDO, Alberto. (1988), Buscando un Inca. Lima, Horizinte.

GUTIÉRREZ, Raquel; GARCÍA, Alvaro; TAPIA, Luis \& PRADA, Raúl. (2002), Democratizaciones plebeyas. Bolivia, Muela del Diablo.

IZQUIERDO, Santiago Villaveces. (2001), “¿Por que Erradicarnos? Entre Bastiones de Poder, Cultura y Narcotráfico". Série Antropologia, 308, UnB.

LAZARTE, Jorge. (1987), "Cogestión y participación: ideología y política del movimiento obrero. a democrática”, in René A. Mayorga, Democracia a la Deriva, La Paz, Ceres/Clacso.

. (2002), "Propuesta para el fortalecimiento de una cultura democrática". Bolivia: visiones del futuro. La Paz, FES/Ildis.

LESSMANN, Robert. (2003), Condiciones politicas: marco para processos de autonomia multicultural. Cochabamba, Sec. Bolívia.

MANSILLA, H. C. F. (1993), "Elite del poder: problemas de gobernabilidad y cultura política en Bolivia”, in Mario Miranda Pacheco (org.), Bolivia en la hora de su modernización, México, Unam.

(2003), El carácter conservador de la nación boliviana. Santa Cruz de la Sierra, El Pais.

MARZAL, Manuel M. (1995), "El mito en el mundo andino ayer y hoy". Antropologica, XIII (13).

MAYER, E. \& Bolton, R. (orgs.). (1980), Parentesco y matrimonio en los Andes. Lima: PUCP/ Fondo Editorial.

MAYORGA, Fernando. (2003), Avatares: ensayos sobre politica y sociedade en Bolivia. Cochabamba, Cesu/UMSS/Memoria Editores.

MURRA, John V. (2002), El mundo andino: población, medio ambiente y economía. Lima, IEP/ Pontifícia Universidad Católica.

NASH, June. (1979), We Eat the mines and the Mines Eat Us. Nova York, Columbia University Press. 
ORTA, Andrew. (2001), "Remembering the Ayllu, remaking the nation: indigenous scholarship and activism in the Andes". The Journal of Latin American Anthropology, 6 (1).

OSSIO, Juan. (1992), Parentesco, reciprocidad y jerarquía en los Andes. Lima, Ed. PUCP.

PLATT, Tristan. (1982), Estado boliviano y ayllu andino: tierra y tributo de norte de Potosí. Lima, IEP.

PUTNAM, Robert D.; LEONARDI, Robert \& NANETTI, Raffaella Y. (1993), Making democracy work: civic traditions in modern Italy. Princeton University Press.

RAMÍREZ, Pablo Mamani. (2004), El rugir de las multitudes: la fuerza de los levantamientos indigenas en Bolivia/Qullasuyu. La Paz, Yachaywasi.

RIVERA CUSICANQUI, Silvia. (1991), “Pedimos la revisión de límites': un episodio de incomunicación de castas en el movimiento de caciques-apoderados de los Andes bolivianos 1919-1921". Reproducción y transformación de las sociedades andinas siglos XVI-XX. Tomo II. Colección 500 años. Quito, Abya-Yala.

SOUSA, Rosinaldo Silva de. (2004), "Narcotráfico y economia ilícita: las redes del crímen organizado em Río de Janeiro". Revista Mexicana de Sociología, LXVI (1).

- (2006), Os cocaleros do Chapare: coca, cocaina e politicas internacionais antidrogas na Bolivia. Brasília, tese de doutorado, UnB. . (2006a), "Trayectorias de bandidos, mitos y ritos del trafico ilícito de drogas en Río de Janeiro". Revista Etnografías Contemporáneas, I (l), Buenos Aires.

TOLEDO, Francisco. ([1569] 1867), Memorial que D. Francisco de Toledo dio al Rey Nuestro Señor, del estado en que dejó las cosas del Perú, después de haber sido en él Virrey y Capitán general, trece años que comenzaron 1569. Lima, Imprenta del Estado por J. E.

WEIL, Connie. (1993), "Problemas de salud asociados con la colonización agricola en Latinoamerica”, in Jim Weil e Weil Connie (eds.). Verde es la esperanza: colonización, comunidad y coca en la Amazonia, Cochabamba/ La Paz, Amigos del Libro.
WEIL, Jim. (1993), "El trabajo cCooperativo: tradición y cambio en las relaciones de producción”, in Jim Weil e Weil Connie (eds.). Verde es la esperanza: colonización, comunidad y coca en la Amazonia, Cochabamba/La Paz, Amigos del Libro.

WOLF, Eric. (1984), As Guerras camponesas do século XX. São Paulo, Global. . (2003), "Tipos de campesinato latino-americano: uma discussão preliminar", in Bela Feldman-Bianco e Gustavo Lins Ribeiro (orgs.), Antropologia e poder: contribuiçóes de Eric Wolf, São Paulo, Editora da UnB/Unicamp/Imesp.

VAN DEN BERG, Hans \& SCHIFFERS, A. (orgs.). (1992), La cosmovisión Aymara. La Paz, Hisbol/UCB.

ZUIDEMA, R. T. (1989), Reyes y guerreros: ensayos de cultura andina. Lima, Fomciencias. 


\section{ORGANIZAÇÃO POLÍTICA E CULTIVOS ILÍCITOS DE COCA NA BOLÍVIA: UMA ABORDAGEM ETNOGRÁFICA}

\section{Rosinaldo Silva de Sousa}

Palavras-chave: cocaleros; cultura política; mundo andino; Bolívia; folha de coca.

A cultura política de um povo é aspecto relevante para a compreensão do relacionamento que mantém com o seu Estado, assim como de suas reivindicações baseadas em noções particulares de justiça e democracia. No caso boliviano, minha abordagem irá privilegiar dois fatores que ajudam a compreender a orientação política e cultural da maioria de origem indígena: (1) a disputa em torno do direito de cultivar a folha de coca, mesmo contrariando a legislação internacional e nacional; e (2) a influência atual de padrôes de ação política ancorados em princípios ancestrais da política andina pré-colombiana. Meu objetivo será mostrar a forma como tanto as estruturas de longa duração, como a aplicação da legislação internacional antidrogas influenciam a conformação da cultura política boliviana.

\section{POLITICAL ORGANIZATION AND ILLICIT COCA CULTIVATION IN BOLIVIA: AN ETHNOGRAPHIC APPROACH}

Rosinaldo Silva de Sousa

Keywords: Cocaleros; Political culture; Andean world; Bolivia; Coca leaf.

The political culture of a peoples is a relevant aspect to understand the relationship they maintain toward its State, as well as their demands based on particular justice and democracy notions. In the Bolivian case, my approach will privilege two factors that help understanding cultural and political orientation of the indigenous majority: (1) the argument around the right to cultivate coca leaf, even if it goes against international and national legislation; and (2) the present influence on political action standards based on ancestral principles of pre-Colombian Andean politics. My goal is to show how both long-lasting structures and the implementation of international anti-drug legislation influence the conformation of the Bolivian political culture.

\section{ORGANISATION POLITIQUE ET CULTURES ILLICITES DE COCA EN BOLIVIE: UN ABORDAGE ETHNOGRAPHIQUE}

\section{Rosinaldo Silva de Sousa}

Mots-clés: cocaleros; culture politique; monde andin; Bolivie; feuille de coca.

La culture politique d'un peuple est un aspect relevant pour la compréhension du rapport qu'il maintient avec son État, ainsi que ses revendication fondées sur des notions particulières de justice et de démocratie. Dans le cas bolivien, mon abordage privilégiera deux facteurs qui aident à comprendre l'orientation politique et culturelle de la majorité d'origine indienne: (1) la dispute à propos du droit à cultiver la feuille de coca, même si cela contrarie la législation internationale et nationale; et (2) l'influence actuelle de modèles d'action politique ancrés sur des principes ancestraux de la politique andine précolombienne. Mon objectif sera de montrer la façon par laquelle tantôt les structures de longue durée que l'application de la législation internationale antidrogues, influencent la conformation de la culture politique bolivienne. 